\title{
Nature of ventricular activation in patients with dilated cardiomyopathy: evidence for bilateral bundle branch block
}

\author{
Han B Xiao, Craig Roy, Derek G Gibson
}

\begin{abstract}
Objective-To investigate the nature of ventricular activation and its relation with mechanical events in patients with
\end{abstract} dilated cardiomyopathy.

Study design-Retrospective and prospective study with 12 lead electrocardiograms, signal averaged electrocardiograms, and $M$ mode and Doppler echocardiograms.

Setting-Tertiary cardiac referral centre. Patients-77 patients (mean (SD) age 59(13)) with dilated cardiomyopathy, four after aortic valve replacement and three after coronary bypass surgery, and six patients with a normal sized left ventricle and complete right bundle branch block were studied. 15 normal subjects (age 45(20)) were used as controls.

Results-In patients with dilated cardiomyopathy, QRS duration was longer (127(25) ms $v 90(10), P<0.05)$ than normal and was normally distributed $(r=$ $0.991, P<0.01$ ) on a normal probability plot. 20 had classic left bundle branch block, 29 intraventricular conduction delay, four right bundle branch block, and one bifascicular block. The PR interval was prolonged (185(30) ms $v$ 150(15), $P<0.05)$. Electromechanical delay, $Q$ to the onset of thickening of the interventricular septum as seen on the transverse $M$ mode echocardiogram, was $75(15) \mathrm{ms}$ in controls, but reduced to $43(15) \mathrm{ms}$ in the patients $(P<0.01)$. $Q$ to the onset of mitral regurgitation was also short (50(15)) $\mathrm{ms}$, and correlated inversely with PR interval $(r=-0.67, n=73, P<0.01)$. Early potentials $(<40 \mu \mathrm{V})$ were recorded on the signal averaged electrocardiogram in 33 representative patients and in all controls. Their overall duration was 30 (12) $\mathrm{ms}$ in the patients, much longer than normal (12(7), $P<0.01)$ ). Early potential time correlated positively with PR interval $(r=0.75, P<0.01)$ and $Q R S$ duration $(r=0.60, P<0.01)$ on a 12 lead electrocardiogram, and negatively with apparent electromechanical delay $(r=$ $-0.71, P<0.01, n=33$ ), but not with true electromechanical delay (73(15) ms) or true PR interval (163(30)ms), calculated by correcting apparent values for early potential. The onset of left ventricular free wall motion was delayed with respect to the septum beyond $95 \%$ of the upper normal limit in all the patients with classic left bundle branch block and intraventricular conduction defect. Motion in the right ventricular free wall was delayed in 13 of 20 patients with left bundle branch block and 24 of 29 with intraventricular conduction defect by 65(20) ms, similar to that $(75(10) \mathrm{ms})$ in patients with right bundle branch block. Conclusion-In most patients with dilated cardiomyopathy and an electrocardiographic pattern of left bundle branch block or intraventricular block, the onset of mechanical systole is strikingly and symmetrically delayed in both ventricles, compatible with bilateral bundle branch block. Complete atrioventricular block does not occur. The ventricle is activated through the upper septum and this activation is detectable only by signal averaged electrocardiography. The anatomical substrates for this abnormal activation could be the high connections described by Mahaim and Winston.

(Br Heart f 1994;72:167-174)

Prolonged ventricular activation, as shown by a broad QRS complex, is common in patients with dilated cardiomyopathy ${ }^{12}$ and may independently impair systolic and diastolic ventricular function. ${ }^{23}$ Such patients are often said to have "left bundle branch block", but the body of direct information from humans underlying this diagnosis is surprisingly scanty. The electrocardiographic pattern in these patients is very variable, particularly as to the presence or absence of a septal q wave. Also, the QRS duration is unimodally distributed in a large population of such patients, ${ }^{2}$ which would be surprising if the long QRS complex were indeed due to the presence or absence of a localised block of a single anatomical structure. In our study, therefore, we have attempted to clarify some of these questions by combining detailed findings of regional ventricular wall motion with information from standard 12 lead and signal averaged electrocardiograms in a group of patients with dilated cardiomyopathy.

\section{Patients and methods}

\section{PATIENTS}

We studied 77 patients aged 59(SD13). All the patients had dilated cardiomyopathy, defined as left ventricular end diastolic dimension $6.0 \mathrm{~cm}$ or more and shortening fraction $<15 \%$ on an $M$ mode echocardiogram. Four 
of the patients had undergone aortic valve replacement and three coronary bypass surgery. Functional mitral regurgitation was present in all the patients; those with any diastolic or presystolic component were excluded. We also studied six patients with normal left ventricular size and complete right bundle branch block, who had secundum atrial septal defect before (one patient) or after (five patients) surgical correction. Fifteen controls (age 45(20)) had normal hearts, and six had palpitation, five soft systolic murmur, two family history of hypertrophic cardiomyopathy, and one atypical chest pain. None showed any significant cardiac abnormalities on physical examination, electrocardiography, chest $x$ ray film, 24 hour tape, or echocardiography. All the controls and patients were in sinus rhythm.

\section{ELECTROCARDIOGRAPHY}

Twelve lead electrocardiograms were recorded with a Hewlett Packard XLi PaperWriter Cardiograph, which computed and printed PR interval, QRS duration, and axis. ${ }^{4}$ A filter of $0.05-100 \mathrm{~Hz}$ was used.

The electrocardiographic criteria for left bundle branch block $^{5}$ were a QRS duration $>120 \mathrm{~ms}$, no septal q waves, and no secondary $R$ wave in right chest leads. If $Q R S$ duration was increased between $110 \mathrm{~ms}$ (the upper limit of normal) and $120 \mathrm{~ms}$, or if QRS duration was $\geqslant 120 \mathrm{~ms}$ and a septal $\mathrm{q}$ wave was present, a diagnosis of intraventricular conduction delay was made. The diagnosis of right bundle branch block was based on secondary $R$ waves in right chest leads with a QRS duration $>120 \mathrm{~ms}$. Those with a broad $\mathrm{QRS}$ complex (>120 ms), secondary $\mathrm{R}$ waves in right chest leads, and left axis deviation $\left(<-30^{\circ}\right)$ were considered to have bifascicular block.

\section{SIGNAL AVERAGED ELECTROCARDIOGRAPHY}

With a Hewlett Packard signal averaging system for late potential analysis, we recorded signal averaged electrocardiograms in 33 patients and all normal controls. The signal averaged electrocardiograms were obtained from orthogonal X, Y, and Z (Frank) leads, at a sampling rate of $2.0 \mathrm{kHz}$ for a mean (SD) of 750 (250) beats. An operator selected template and a high pass filter of $40 \mathrm{~Hz}$ were used. Data were collected until the final noise level was $0 \cdot 49(0 \cdot 10) \mu \mathrm{V}$ and the acceptance rate was over $98 \%$. We defined the signals with an amplitude $<40 \mu \mathrm{V}$ during the initial part of the QRS complex as early potentials, and measured their overall duration (fig 1). Late potential time was determined from built in software.

\section{ECHOCARDIOGRAPHY}

Echocardiograms were recorded with a Hewlett Packard Sonos 1000 system and a 2.5 $\mathrm{MHz}$ transducer. We recorded transverse left ventricular motion just at the tips of the leaflets of the mitral valve with cross sectional image guided $\mathrm{M}$ mode echocardiograms. Longitudinal $\mathbf{M}$ mode echocardiograms were recorded in three sites, both lateral left and right atrioventricular junctions, and the central fibrous body. ${ }^{6}$ All the $M$ mode echocardiograms were recorded photographically at a paper speed of $100 \mathrm{~mm} / \mathrm{s}$, with simultaneous lead II electrocardiograms and phonocardiograms. The onset of the QRS complex was used as zero to measure: $(a)$ the time to the
Figure 1 Signal averaged electrocardiograms recorded in a normal control $(A)$ and a patient (B) with dilated cardiomyopathy and classic left bundle branch block pattern on standard 12 lead electrocardiogram. The early potential time (arrows) is much longer in the patient than in the control.

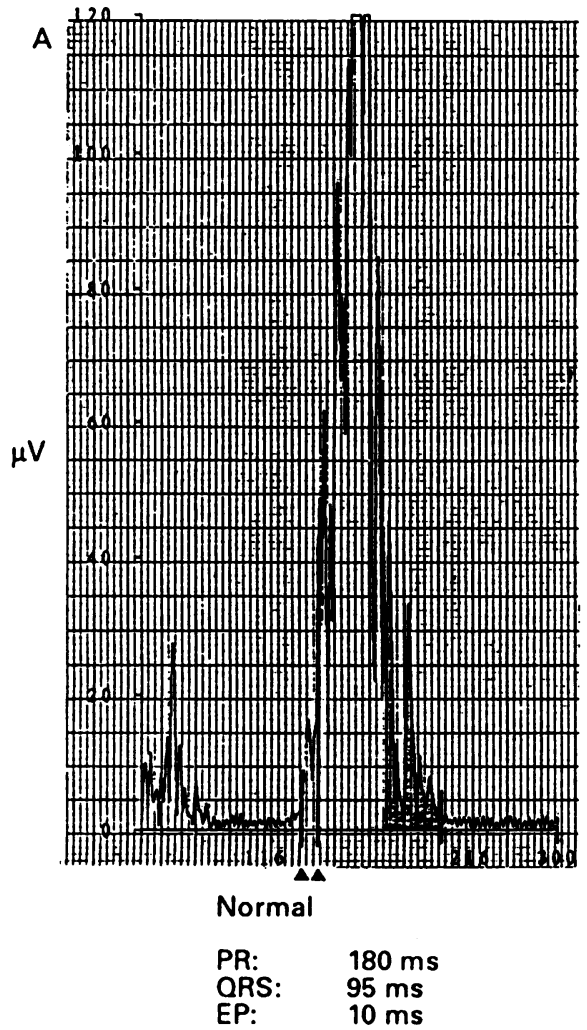

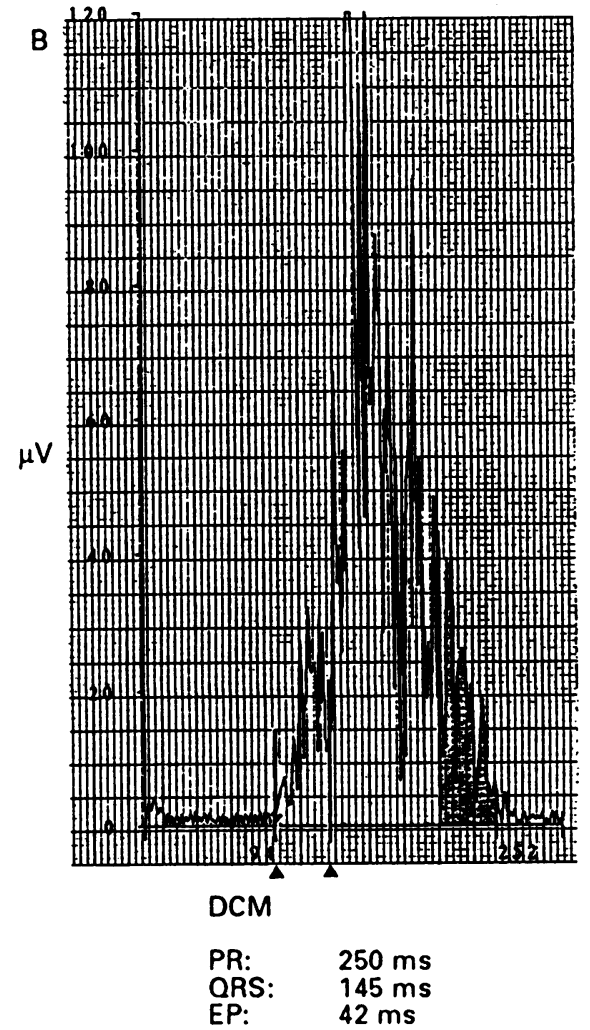


Figure 2 Longitudinal $M$ mode echocardiogram of the right atrioventricular junction recorded in a normal control. Vertical lines mark the time of $Q$ and the onset of systolic shortening.

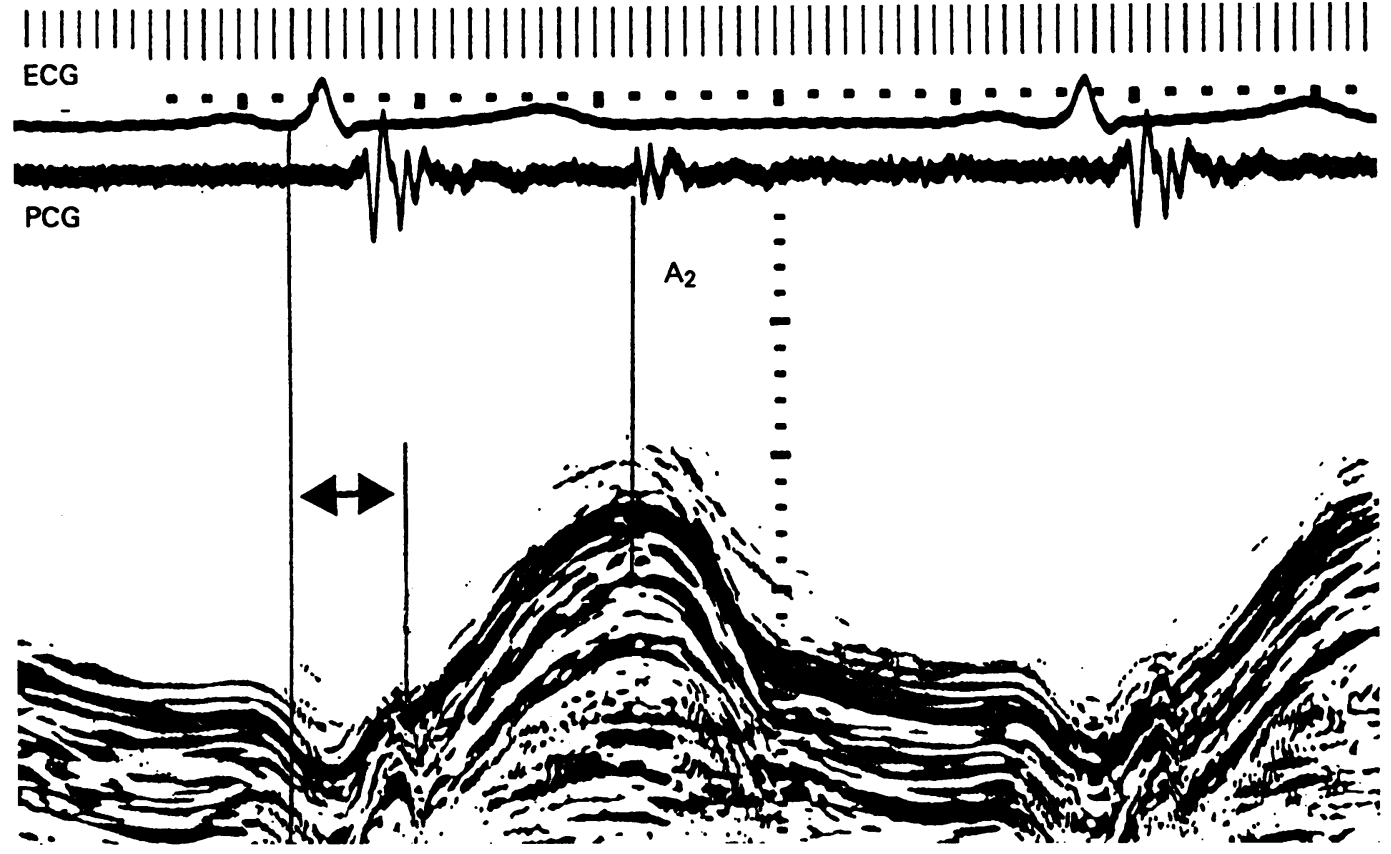

onset of transverse septal and posterior wall thickening; (b) the time to the onset of longitudinal ventricular motion in all sites (fig 2 ); (c) relative delays in the onset of systolic motion of the posterior left ventricular wall, and long axis motion of the left and right ventricular free wall with respect to the onset of transverse septal contraction.

\section{DOPPLER ECHOCARDIOGRAPHY}

Functional mitral regurgitation was recorded in continuous wave mode with a Doptek Spectrascan and a $2.0 \mathrm{MHz}$ pencil transducer, and was used as a simple measure of the time course of left ventricular pressure. ${ }^{27}$ Again, with simultaneous electrocardiograms and phonocardiograms, the records were made at a paper speed of $100 \mathrm{~mm} / \mathrm{s}$. We measured electromechanical delay as the time from the onset of the QRS complex to that of mitral regurgitation. We also measured the overall duration of mitral regurgitation, left ventricular contraction, and relaxation times. ${ }^{3}$

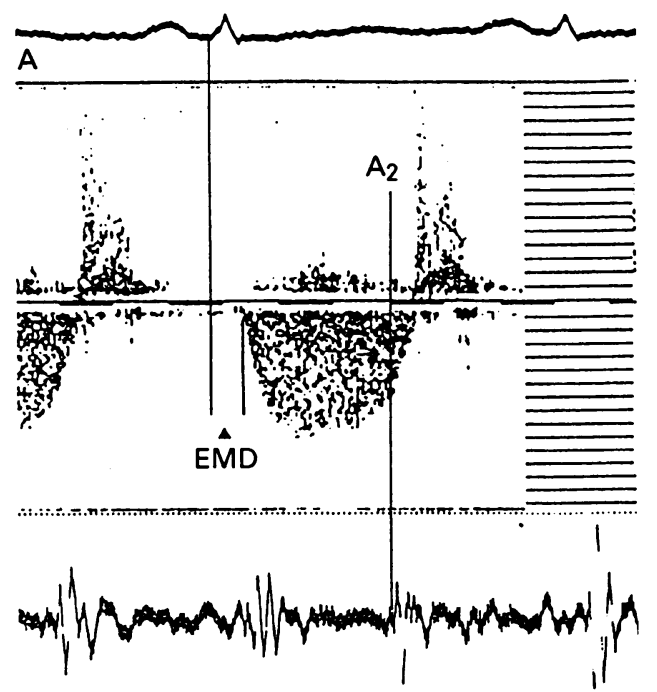

DATA ANALYSIS

All the echocardiographic measurements were made on three successive cardiac cycles and average values were taken. They were expressed as mean (SD). A normal probability plot was used to judge the distribution of the values of $\mathrm{QRS}$ duration. ${ }^{8}$ Linear regression analysis was performed by the method of least squares. An unpaired Student's $t$ test or analysis of variance was used to assess differences between mean values.

\section{Results}

\section{LEAD ELECTROCARDIOGRAM}

In patients with dilated cardiomyopathy, QRS $v 90(10), P<0.05)$ than normal, and was normally distributed $(r=0.991, P<0.01)$. Twenty of the patients had electrocardiographic features of classic left bundle branch block, 29 intraventricular conduction delay (QRS duration $>120 \mathrm{~ms}$ in 19), four right


duration was significantly longer $(127(25) \mathrm{ms}$
Figure 3 Functional mitral regurgitation recorded by continuous Doppler (full scale deflection $=16 \mathrm{kHz}$ ) in a patient $(A)$ with normal $P R$ interval $(150 \mathrm{~ms})$ and $Q R S$ duration $(80 \mathrm{~ms})$ and in a patient (B) with prolonged $P R$ interval (220 ms) and $Q R S$ duration $(165 \mathrm{~ms})$. Note that the electromechanical delay (EMD), from the onset of $Q$ wave on the electrocardiogram to that of mitral regurgitation in $(B)$ is much shorter ( $25 \mathrm{~ms}$. $60)$ than that in $(A)$. 
Figure 4 Relation between $P R$ interval and (A) apparent electromechanical delay (EMD) derived from standard 12 lead electrocardiogram in the whole population, or (B) those who had signal averaged

electrocardiograms, and (C) the correlation of $P R$ interval with true EMD delivered from signal averaged electrocardiogram.
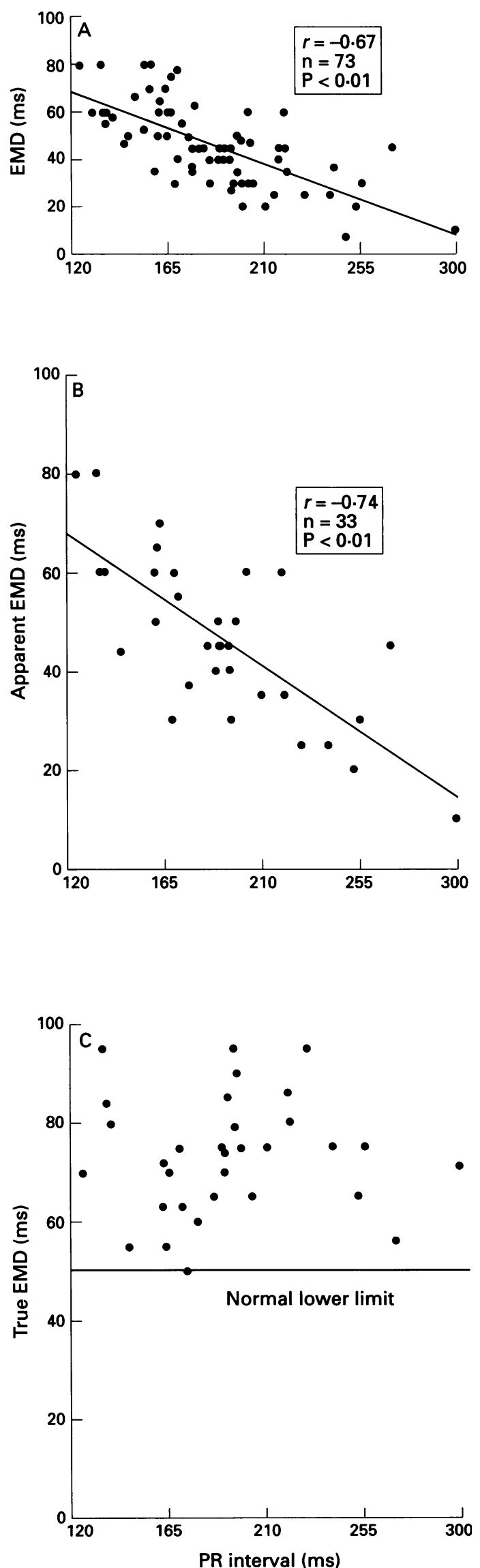

bundle branch block, and one bifascicular block. The remaining 23 had normal QRS duration with (five patients) or without left axis deviation. The PR interval was often long (185(30) $v 150(15) \mathrm{ms}, \mathrm{P}<0.05)$ and its duration correlated positively with QRS duration $(r=0.45, \mathrm{P}<0.01)$.

\section{EARLY MECHANICAL EVENTS}

The earliest evidence of left ventricular systole in both controls and patients was thickening of the interventricular septum as seen on the transverse $M$ mode echocardiogram. Its onset followed that of the QRS complex by 75(15) $\mathrm{ms}$ in controls, and by $43(15) \mathrm{ms}$ in the patients $(P<0.01)$. Electromechanical delay measured from $Q$ to the onset of mitral regurgitation was $50(15) \mathrm{ms}$, occurring within 10 ms of the onset of the septal thickening in all patients. Electromechanical delay correlated inversely with the PR interval $(r=-0.67$, $n=73, \mathrm{P}<0.01$, figs 3 and $4(A)$ ).

\section{SIGNAL AVERAGED ELECTROCARDIOGRAM}

Early potentials were recorded on signal averaged electrocardiograms in 33 representative patients whose clinical, electrocardiographic, and mechanical characteristics did not differ in any way from the rest (table 1 ). Their overall duration was 30 (12) ms, much longer than that in normal controls $(12(7) \mathrm{ms}, \mathrm{P}<0.01)$. In individual patients, the early potential time correlated positively with the PR interval $(r=$ $0.75, \mathrm{P}<0.01)$ and $\mathrm{QRS}$ duration $(r=0.60$, $P<0.01$ ) on 12 lead electrocardiogram. These early potentials were directed anteriorly in all but two, from left to right in 21 , and right to left in 12 .

The QRS duration on the signal averaged electrocardiogram (QRSDs) was significantly longer than that on the 12 lead electrocardiogram (QRSD12) (150(40) ms v 130(30), P < 0.01 ) although the values obtained by the two methods correlated closely $(r=0.94$, QRSD12 (ms) $=0.815 \times$ QRSDs $+10, P<$ 0.01 for both slope and constant). This prolongation was due to early as well as late potentials $(60(35) \mathrm{ms})$. Late potential time also correlated with QRS duration $(r=0.64$, $P<0.01)$ but not with early potential time $(r=$ $0 \cdot 28, \mathrm{NS})$.

The time of early potentials correlated negatively with apparent electromechanical delay $(r=-0.71, \mathrm{P}<0.01, n=33)$ derived from the 12 lead electrocardiogram. True electromechanical delay (73(15) ms) was calculated by adding the early potential time to the

Table 1 Comparison between the patients who had signal averaged electrocardiograms and those who had not

\begin{tabular}{|c|c|c|}
\hline & $\begin{array}{l}\text { Patients with } \\
\text { SAECG recorded } \\
(n=33)\end{array}$ & $\begin{array}{l}\text { Patients without } \\
\text { SAECG recorded } \\
(n=44)\end{array}$ \\
\hline $\begin{array}{l}\text { Age (yr) } \\
\mathrm{RR} \text { interval (ms) } \\
\text { Left ventricular end } \\
\quad \text { diastolic dimension }(\mathrm{cm})\end{array}$ & $\begin{array}{l}60(13) \\
700(175) \\
7 \cdot 1(1 \cdot 0)\end{array}$ & $\begin{array}{l}59(10) \\
725(150) \\
7 \cdot 1(0 \cdot 9)\end{array}$ \\
\hline $\begin{array}{l}\text { PR interval (ms) } \\
\text { QRS duration (ms) } \\
\text { Electromechanical delay } \\
\text { (ms) }\end{array}$ & $\begin{array}{l}190(40) \\
130(33) \\
48(19)\end{array}$ & $\begin{array}{l}181(285) \\
124(25) \\
47(7)\end{array}$ \\
\hline $\begin{array}{l}\text { Overall duration of } \mathrm{MR} \\
\text { (ms): }\end{array}$ & $450(65)$ & $445(60)$ \\
\hline $\begin{array}{l}\text { Contraction time } \\
\text { Ejection time } \\
\text { Relaxation time }\end{array}$ & $\begin{array}{l}93(35) \\
255(35) \\
98(25)\end{array}$ & $\begin{array}{l}90(35) \\
250(40) \\
105(25)\end{array}$ \\
\hline
\end{tabular}

All values NS. Values are mean (SD). MR, mitral regurgitation; SAECG, signal averaged electrocardiogram. 
Table 2 Relation between PR interval and electromechanical delay (EMD)

\begin{tabular}{lll}
\hline & $\begin{array}{l}\text { Apparent EMD } \\
(48(15) \mathrm{ms})\end{array}$ & $\begin{array}{l}\text { Corrected EMD } \\
(73(15) \mathrm{ms})\end{array}$ \\
\hline $\begin{array}{ll}\text { PR interval } \\
(185(25) \mathrm{ms})\end{array}$ & $-0.74^{\star \star}$ & -0.26 \\
$\begin{array}{l}\text { Corrected PR interval } \\
(163(30) \mathrm{ms})\end{array}$ & $-0.53^{\star}$ & -0.35 \\
\hline${ }^{\star} \mathrm{p}<0.05 ;{ }^{\star \star} \mathrm{p}<0.01$. & \\
\hline
\end{tabular}

apparent value, and the true $P R$ interval was derived by subtracting it. When this was done, the close correlation of electromechanical delay with the PR interval disappeared (table 2 , fig $4(B$ and $C))$. The interval from the $Q$ wave to the onset of interventricular septal thickening was also corrected by adding early potential time to the apparent value. Once this was done differences among groups were no longer apparent (table 3 ).

\section{ONSET OF MECHANICAL ACTIVITY ON BOTH SIDES OF THE HEART}

Table 3 shows the relative delay in the onset of motion of the left and right ventricular free walls and the comparison among the groups. Compared with the upper limit of the normal $95 \%$ confidence interval ( $95 \% \mathrm{CI}), 45 \mathrm{~ms}$ for left, $50 \mathrm{~ms}$ for right, and $55 \mathrm{~ms}$ for left posterior wall, we noted that the onset of left ventricular free wall motion was equally delayed in all the patients with classical left bundle branch block and intraventricular conduction defect; the onset of the right ventricular free wall motion was delayed in 13 out of 20 patients with left bundle branch block and 24 out of 29 with intraventricular conduction defect to an extent similar to that seen in patients with right bundle branch block.

\section{CLINICAL CORRELATIONS}

In the 12 patients with left bundle branch block or intraventricular conduction delay who had normal onset of right ventricular wall motion, two had developed conduction abnormalities during aortic surgery and two had previously undergone coronary arterial bypass grafting. Patients with delayed onset of right free wall motion (six patients) had a longer early potential time $(35(11) \mathrm{ms} v$ $12(6.0), P<0.01)$ than those without delay (seven patients), in whom it was effectively normal. In the presence of right bundle branch block, the left free wall motion was also delayed in three out of the four patients with a dilated left ventricle but not in any of the patients with an atrial septal defect.

\section{Discussion}

The conclusions of this study are unorthodox. We had assumed that a broad QRS complex in patients with left ventricular disease was due either to intraventricular conduction delay or to bundle branch block if the appropriate electrocardiographic criteria ${ }^{59}$ were fulfilled. The site of this block we took to be left sided in most patients, and to be peripheral rather than central. In such patients, we believed that the left ventricle was activated through the septum from the right ventricle, whose conduction system remained intact. Complete block of both left and right branches of the bundle of His would, we assumed, lead inevitably to complete heart block. A long PR interval, often present in patients with severe left ventricular disease, we took to be the result of a related conduction disturbance. As our results became incompatible with these widely held assumptions, our experimental design had to vary as the investigation progressed.

If a broad QRS complex on the electrocardiogram were, in fact, caused by a block in one or other branches of the bundle of His, one would expect the onset of mechanical activity of the appropriate ventricle to be delayed. In patients with a right bundle branch block pattern on the electrocardiogram this conclusion was confirmed, with systolic motion of the right ventricular long axis starting an average of $55 \mathrm{~ms}$ later than normal. On the left side of the heart a similar delay would be anticipated in patients with the electrocardiographic pattern of left bundle branch block, provided the underlying abnormality was a discrete proximal interruption of the pathway. If the abnormality was an arborisation block, the time of onset could be normal. In fact, we found the electromechanical delay to be abnormally short in our patients. This was apparent either when the earliest wall thickening, usually in the septum, or the onset of functional mitral regurgitation was taken as evidence of the onset of mechanical activity, these two events being effectively synchronous. It also seemed that the PR interval was often long, and that there was a clear inverse correlation between this lengthening and the electromechanical delay. This combination of short electromechanical delay and long PR interval strongly suggested that the onset of the QRS complex on the 12 lead electrocardiogram did not mark the true onset of ventricular activation.

To investigate this hypothesis, we used sig-

Table 3 Relative time intervals of regional wall motion (ms)

\begin{tabular}{|c|c|c|c|c|}
\hline & $\begin{array}{l}\text { Normal } \\
(n=15)\end{array}$ & $\begin{array}{l}\text { Right bundle } \\
\text { branch block } \\
(n=6)\end{array}$ & $\begin{array}{l}\text { Intraventricular } \\
\text { conduction defect } \\
(n=29)\end{array}$ & $\begin{array}{l}\text { Left bundle } \\
\text { branch block } \\
(n=20)\end{array}$ \\
\hline $\begin{array}{l}Q \text { to septal thickening } \\
\text { Corrected } Q \text { to septal thickeningt } \\
\text { Septum to left ventricular posterior wall } \\
\text { Septum to left free wall } \\
\text { Septum to right free wall }\end{array}$ & $\begin{array}{l}75(15) \\
82(12) \\
30(13) \\
20(12) \\
20(14)\end{array}$ & $\begin{array}{l}75(15) \\
35(15) \\
27(25) \\
75(10)\end{array}$ & $\begin{array}{l}43(14)^{\star \star} \\
75(12) \\
85(30)^{\star \star} \\
95(30)^{\star \star} \\
65(25)^{\star \star}\end{array}$ & $\begin{array}{r}43(12)^{\star \star} \\
78(15) \\
100(25)^{\star \star} \\
100(30)^{\star \star} \\
65(25)^{\star \star}\end{array}$ \\
\hline
\end{tabular}

$\star \star \mathrm{p}<0.01 v$ normal. Values are mean (SD).

† Assuming $40 \mu \mathrm{V}$ to be the minimum potential recorded by 12 lead electrocardiography, and with a sample size of 15 , for normal, 12 for intraventricular conduction defect, and left bundle branch block. 
nal averaged electrocardiography to detect potentials too low to appear on the standard 12 lead electrocardiogram. By analogy with late potentials, ${ }^{10-12}$ we defined early potentials as those below $40 \mu \mathrm{V}$ occurring at the start of ventricular activation, and measured their overall duration in the same way. The upper limit of normal for the duration of such potentials was $25 \mathrm{~ms}$. In patients with dilated cardiomyopathy, in contrast, this was significantly increased, up to $60 \mathrm{~ms}$. The extent of this lengthening correlated directly with PR interval and QRS duration and inversely with electromechanical delay. Furthermore, when these early potentials were taken into account in defining the true onset of activation, electromechanical delay and the PR interval reverted to normal, and their relation was lost. The time interval from the $Q$ wave to the onset of interventricular septal thickening was corrected in the same fashion. This abolished the difference between patients and normal controls. We believe, therefore, that these early potentials underlie the very short apparent electromechanical delay seen in these patients, a finding that would otherwise be hard to explain. Also, we suggest that much of the apparent lengthening of the PR interval is not due to an increase in the interval between the onset of atrial activation and that of the ventricle, but is due to a further delay between the true onset of ventricular activation and its earliest appearance on the 12 lead electrocardiogram.

The existence of early potentials raised further theoretical problems. In particular, it was not immediately clear how they could have arisen at all if, as is generally believed, the left ventricle in the presence of left bundle branch block is activated through the septum from the right, where activation is assumed to be normal. The duration of these early potentials, up to $60 \mathrm{~ms}$, is incompatible with normal right sided activation. To investigate this matter further, therefore, we observed the onset of mechanical movement of the right ventricle, using longitudinal motion of the right atrioventricular junction as an index. We found movement of the right ventricular septum to be delayed in most patients with dilated cardiomyopathy to the same extent as seen in those with uncomplicated right bundle branch block. Those in whom it was not delayed did not have abnormal early potentials. To explain our findings, we were forced to assume that many of the patients with dilated cardiomyopathy effectively had both right and left bundle branch block. This occurred in the absence of 12 lead electrocardiographic evidence of right bundle branch block and, more significantly, of complete heart block.

We believe that it is possible to explain these apparently anomalous findings, although at the expense of abandoning some traditional ideas on electrocardiography. The combination of the mechanical features of right and left bundle branch block without complete heart block indicates that ventricular activation must be occurring through some proximal route in the bundle of His. The normal or long PR interval, even when corrected for early potentials, indicates that this pathway must be either low in the atrioventricular node, or more probably distal to it. The normal corrected electromechanical delay seen on the left side showed that early potentials are associated with activation of the functioning myocardium and are not confined to the conduction system, which we assume to be without contractile activity. The site of this early contraction can be localised by $M$ mode echocardiography, and shown to be the basal and mid-septum. We conclude, therefore, that our results, although unorthodox, are internally consistent, and can be explained by assuming that ventricular activation proceeds through fibres that arise from the conduction system between the low atrioventricular node and the proximal bundle, and are inserted into the myocardium of the upper septum. As the potentials are so low, the absolute mass of muscle involved is probably small. This, in combination with their duration, suggests that conduction velocities must be low and that subsequent spread is myogenic rather than through specialised conduction fibres. Finally, the direction of the vector of these early potentials is either from left to right or vice versa and suggests that this early activated myocardium may be localised on either side of the septum.

A mechanism of ventricular activation such as that we have outlined should be amenable to anatomical proof. We have, as yet, no such direct information. The pathway whose existence we have deduced closely resembles that described by Mahaim and Winston on the basis of multiple serial sections. ${ }^{13}$ They delineated, in a series of mammalian hearts including human ones, high connections or fibres, the anatomy, diameter, and number of which were all very variable between individual hearts. Their histology was that of the conduction system and, in humans, they arose from the atrioventricular bundle. They either passed directly to septal muscle from the bundle, or less commonly arose and ended in the bundle, but came into contact with the myocardium in their mid-portion. Mahaim and Winston also investigated their physiological significance in laboratory animals. They noted that section of both branches of the main bundle did not necessarily lead to complete heart block, only doing so when the high connections were small and scanty. Provided that the high fibres were well developed, the only effect of section of both bundles was to prolong the PR interval. They introduced the term "bloc bilatéral manqué" to describe this state of affairs. Two years later, Mahaim and his colleagues were able to document complete interruption of both bundles by fibrosis at necropsy in a patient with severe left ventricular disease, whose electrocardiogram showed what would now be described as classical left bundle branch block with atrial flutter and a normal ventricular rate. ${ }^{14}$ These effects must, of course, be differentiated from certain tachycardias of left bundle branch block con- 
figuration, which have also been ascribed more recently to Mahaim fibres. ${ }^{15} 16$ The relation of these nodoventricular fibres to the arrhythmias that they are alleged to mediate remains problematic. In contrast, the combination of bilateral block, long PR interval, and absence of complete heart block corresponds closely with the original physiological and clinical descriptions of Mahaim and his colleagues.

Our study clearly has limitations. The possibility arises that the apparently short electromechanical delay seen in our patients represented the end of left atrial activity or, in the case of functional mitral regurgitation, that a presystolic component was present. We therefore took the onset of septal thickening rather than the start of inward motion to avoid this possibility. We have also found an abnormally short electromechanical delay in patients with atrial fibrillation in whom an atrial component was clearly not involved (fig 5). The exact technique of measurement of early potentials was arbitrary. We have not established a clear threshold at which voltages appear on the standard 12 lead electrocardiogram, although both absolute value and rate of rise seem to be important. The value of 40 $\mu \mathrm{V}$ was therefore used by analogy with late potentials. Apart from causing apparent prolongation of the PR interval, the presence of early potentials did not seem to modify the standard 12 lead electrocardiogram in any consistent way; in particular, there was no relation with the presence or absence of septal $q$ waves. It might have been expected that the delayed right ventricular activation, shown to be present in many of our cases on mechanical grounds would have had some influence on QRS configuration. We cannot identify any such pattern and have no direct evidence on why we were unable to do so. Nevertheless, we do not consider this to be an insuperable objection, bearing in mind the well known effect of left bundle branch block in masking $Q$ wave evidence of myocardial infarction.

The results of our study have several implications. They have shown that ventricular activation may be more abnormal than has previously been thought in patients with ventricular disease. They explain the striking lengthening of functional mitral regurgitation, and thus the development of left ventricular pressure in some of these patients, findings previously attributed to impaired contractility. ${ }^{1718}$ They also explain why the time course of right ventricular systolic pressure may also be long. ${ }^{1920}$ It has become clear that what is described as left bundle branch block in humans is different from an experimental model in which the left branch of the bundle of His has been interrupted. The additional presence of right bundle branch block also provides a more convincing explanation for differing effects of right ventricular pacing and left bundle branch block on left ventricular function than any we were previously able to offer. ${ }^{21}$ This indicates that the left ventricle can be activated from the right, and that when this occurs, the time of the rise in left ventricular pressure is significantly reduced. The presence of this masked right bundle branch block further extends a historical debate on the nature of bundle branch block that has already lasted for over 70 years. ${ }^{22-24}$ It may also be related to cardiac death from bradycardia rather than from malignant ventricular
Figure 5 Functional mitral regurgitation on a continuous Doppler trace in a patient with atrial fibrillation and dilated cardiomyopathy, showing $a$ very short

electromechanical delay (EMD) ( $Q$ to onset of mitral regurgitation).

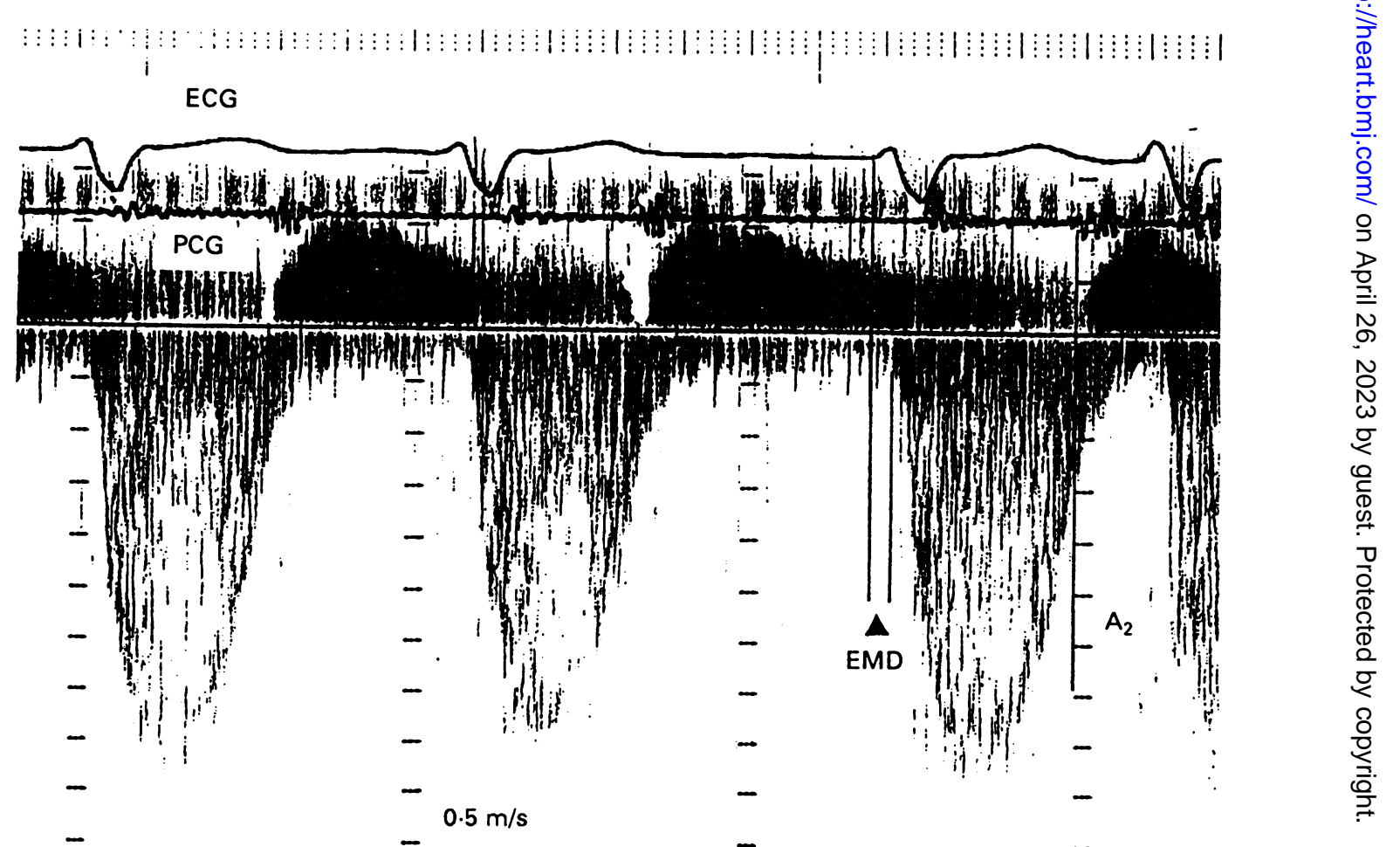


tachycardia in patients with advanced congestive heart failure. ${ }^{25}$ Even so, it does not seem impossible that the region of slow conduction high in the interventricular septum might be a potential source of ventricular arrhythmias due to sustained bundle branch re-entry, which has been found almost exclusively in patients with dilated cardiomyopathy or congestive heart failure. ${ }^{26}$ These patients usually have inducible monomorphic ventricular tachycardia and similar electrocardiographic findings as in our patients - that is, an intraventricular conduction defect characterised by a long QRS duration and HV interval (PR interval) and no complete heart block. ${ }^{26} \mathrm{We}$ suggest, therefore, that combining electrical and mechanical findings has proved fruitful in investigating disturbances of ventricular activation. To show the profound functional effects of these abnormalities may open the way for more effective treatment than has been possible by pharmacological means.

We thank Professor Robert $\mathrm{H}$ Anderson for his useful advice in preparing this paper. HBX is supported by the Royal Brompton Hospital Special Cardiac Fund.

1 Rahko PS, Shaver JA, Salerni R. Evaluation of mechanica events and systolic function in dilated cardiomyopathy: comparison between patients with and without left bundle branch block. Acta Cardiol 1988;43:179-84.

2 Xiao HB, Brecker SID, Gibson DG. Effects of abnorma activation on the time course of the left ventricular pressure pulse. Br Heart $\mathcal{F}$ 1992;68:103-7.

3 Xiao HB, Lee CH, Gibson DG. Effect of left bundle branch block on diastolic function in dilated cardiomyopathy. Br Heart $\mathcal{F} 1991 ; 66: 443-7$.

4 Hewlett Packard Company. Page Writer XLi Cardiograph physician's guide. 2nd ed. Boston:Hewlett Packard physician's guide. 2nd

5 Willems, JL, De Medina EOR, Bernard R, et al. Criteria for intraventricular conduction disturbances and prefor intraventricular conduction disturbances

6 Jones CJH, Raposo L, Gibson DG. Functional importance of the long axis dynamics of the human left ventricle. $\mathrm{Br}$ of the long axis dynamics

7 Chen C, Rodriguez L, Guerrero JL, et al. Noninvasive estimation of the instantaneous first derivative of left ventricular pressure using continuous-wave Dopple echocardiography. Circulation 1991;83:2101-10.
8 Bland M. Normal distribution. In: Oxford medical publications. An introduction to medical statistics. Oxford: Oxford University Press, 1987:112-31.

9 Rowlands DJ. Intraventricular conduction disturbance. In: Rowlands DJ, ed. Clinical electrocardiography. London: Gower Medical Publishing, 1991:110-43.

10 Breithardt G, Cain ME El-Sherif N et al Standards for analysis of ventricular late potentials using high-resoluanalysis of ventricular late potentials using high-resolution or signal-averaged electrocardiography. A statement by a task force committee of European Society of
Cardiology, the American Heart Association, and the Cardiology, the American Heart Association, and the America

11 Vatterott PJ, Hammill SC, Osborn MJ. Clinical application of the signal-averaged electrocardiogram and "late potentials". F Electrocardiol 1992;22 (suppl): 13-8.

12 Denereaz D, Zimmermann M, Adamec R. Significance of ventricular late potentials in non-ischaemic dilated cardiomyopathy. Eur Heart $\mathcal{F}$ 1992;13:895-901.

13 Mahaim I, Winston MR. Récherches d'anatomie comparée et de pathologie experimentale sur les connexions hautes du faisceau de His-Tawara. Cardiologia 1941;5: 189-260.

14 Mahaim I, Winston MR, Roesler $H$. Bilateral missed block. Report of a case in which there was left bundle branch block during life, with autopsy. Am Heart $\mathscr{J}$ 1943;25:251-5.

15 Ellebogen KA, Ramirez NM, Packer DL, et al. Accessory nodoventricular (Mahaim) fibres: a clinical review. PACE 1986;9:868-84

16 Lau CP, Davies DW, Mehta D, Ward DW, Camm AJ Flecainide acetate in the treatment of tachycardias associated with Mahaim fibres. Eur Heart $₹$ 1987;8:832-9.

17 Mason DT, Braunwald E, Covell JW, Sonnenblick EH, Ross Jr, J. Assessment of cardiac contractility. The relation between the rate of pressure rise and ventricular pressure during isovolumic systole. Circulation 1971;44: 47-58.

18 Nakayama Y, Shimizu G, Hirota $Y$, et al. Functional and histopathologic correlation in patients with dilated cardiomyopathy: an integrated evaluation by multivariate analysis. $\Im$ Am Coll Cardiol 1987;10:186-92.

19 Brecker SJD, Xiao HB, Sparrow J, Gibson DG. Effects of dual-chamber pacing with short atrioventricular delay in dilated cardiomyopathy. Lancet 1992;340:1308-12.

20 Brecker SJD, Xiao HB, Stojnic BB, Mbaissouroum M, Gibson DG. Assessment of the peak tricuspid regurgitation velocity from the dynamics of retrograde flow. Int $f$ Cardiol 1992;34:267-71.

21 Xiao HB, Brecker SJD, Gibson DG. Differing effects of right ventricular pacing and left bundle branch block on left ventricular function. Br Heart $₹$ 1993;69:166-73.

22 Oppenheimer BS, Pardee HEB. The site of the cardiac lesion in two instances of intraventricular heart block. Prac Soc Exp Biol Med 1920;17:177-9.

23 Hollman A. The history of bundle branch block. Med Hist 1985;5:82-102.

24 Flowers NC. Left bundle branch block: a continuously evolving concept. $\Im$ Am Coll Cardiol 1987;9:684-97.

25 Luu M, Stevenson WG, Stevenson LW, Baron K, Walden $J$. Diverse mechanisms of unexpected cardiac arrest in advanced heart failure Circulation 1989;80:1675-80.

26 Caceres J, Jazayeri M, McKinnie J, et al. Sustained bundle branch reentry as a mechanism of clinical tachycardia. Circulation 1989;79:256-70. 